\title{
Experimental Investigation on the Effect of Carbon Fiber Reinforcements in the Mechanical Resistance of 3D Printed Specimens
}

\author{
A. F. Calles ${ }^{1} \cdot$ D. Carou ${ }^{1,2}$ (D) R. T. Luiz Ferreira ${ }^{3}$
}

Received: 9 August 2021 / Accepted: 5 November 2021 / Published online: 1 December 2021

(c) The Author(s) 2021

\begin{abstract}
In the last years, fiber-reinforced polymer composites have been under study for additive manufacturing. For this purpose, it is important to assess the behavior of these materials in terms of mechanical properties. The present experimental study evaluates the mechanical resistance of both PLA and carbon fiber reinforced PLA. The work used a full factorial Design of Experiments (108 tests) selecting as factors the infill density, infill pattern, material, number of perimeters and printing orientation. The main results highlight that the most influential factors on the tensile strength are both type of material and number of perimeters. In this study, the use of reinforcements did not improve the mechanical resistance attained by the corresponding virgin material. Particularly, for some selected specimens, the porosity measured in the fracture section is larger for the reinforced PLA specimens, so they showed a smaller cross-section.
\end{abstract}

Keywords 3D printing $\cdot$ Carbon fiber $\cdot \mathrm{FFF} \cdot$ Mechanical properties $\cdot$ PLA $\cdot$ Polymers · Reinforcement

\section{Introduction}

Though some precursors of additive manufacturing (commonly known as 3D printing) such as Joseph E. Blanther, Pierre Alfred Leon Ciraud and Hideo Kodama are well known, it is Charles Hull, founder of 3D Systems, who is often identified as the 3D printing inventor in the 1980s due to his patent for the stereolithography process. Nonetheless, Hull developed the STL file format for this manufacturing process, which currently remains the standard format in 3D printing slicers [9, 19, 32, 39]. Since the 1980s, additive manufacturing has

D. Carou

diecapor@uvigo.es

1 Department of Mechanical and Mining Engineering, University of Jaén, Campus Las Lagunillas, 23071 Jaén, Spain

2 Departmento de Deseño Na Enxeñaría, Universidade de Vigo, Campus As Lagoas, 32004 Ourense, Spain

3 GPMA - Research Group On Additive Manufacturing, ITA - Instituto Tecnológico de Aeronáutica, DCTA ITA IEM, São José dos Campos, São Paulo 12228-900, Brazil 
been increasing its popularity by means of affordable desktop solutions that have become accessible due to the expiration of original patents [19] and by Adrian Bowyer's RepRap project [18].

Additive manufacturing market forecasts are positive about the growth of the market in the coming years, up to 2023/2025, as reviewed by Altıparmak et al. [2] and Peng et al. [36]. The technology is one of the key components of industry 4.0 or smart manufacturing due to its suitability for mass customization [28] and being applied in applications such as manufacturing, civil engineering, automotive engineering, biomedical engineering, food and clothing $[44,49]$.

Fused filament fabrication (FFF), which Stratasys has been operating commercially as fused deposition modeling (FDM) since 1991, is currently one of the most expanded additive manufacturing technologies [46]. Material extrusion is the basis of the process. A thermoplastic material is heated above its melting temperature at an extruder and deposited onto a bed using a layer-by-layer strategy through a nozzle tip. Then, the material solidifies shortly after deposition and incrementally creates the final shape of the part $[3,16]$. Polymer materials, usually supplied as thermoplastic filaments, are widely used in additive manufacturing applications. Among others, some of the most common materials used in FFF are the polylactic acid (PLA) and the acrylonitrile butadiene styrene (ABS) [14, 45]. Thermoplastics like polyether ether ketone (PEEK) and polyethylenimine (PEI) are also available, but they usually require advanced printers in terms of temperature control. Other additive manufacturing processes such as laminated object manufacturing, binder jetting and selective laser sintering were developed to increase the applications to other materials such as ceramics and metals $[4,46]$.

The development of additive manufacturing goes hand in hand with the development of new materials such as the composite materials $[11,12,22,50]$. These materials have found a wide number of applications in sectors such as automotive and aerospace [8,40]. It is critical to understand the capabilities and limitations of the composite materials to use them in 3D printing, particularly, to understand the influence of both short and continuous carbon fiber reinforcements [31, 47]. Regarding, continuous reinforcements, for instance, HeidariRarani et al. [17] showed how tensile and bending strengths of continuous carbon fiber reinforced PLA outperformed those of pure PLA.

Short carbon fiber reinforcement composites are found to be a good material for various additive manufacturing technologies expecting advantages in strength, stiffness, creep resistance, thermal expansion, or toughness, depending on the type of fiber used [47]. For instance, Ning et al. [34] presented a study in which several carbon-fiber reinforced ABS specimens were fabricated and tested, proving that tensile strength and Young's moduli could be improved. The authors also identified the influence of factors such as fiber length and reinforcement percentage. However, issues such as void formation as identified by Tekinalp et al. [41] may compromise the results of the process.

Table 1 shows some recent studies on the use of polymers reinforced by short carbon fibers. The work by Tekinalp et al. [41], Ning et al. [34], Ferreira et al. [12] and Blok et al. [5] are focused on aspects regarding mechanical characterization of such 3D printed composites, basically under tensile, flexural and shear tests, quantifying elastic and strength properties. Nevertheless, several printing parameters and 3D printer setting influence the mechanical properties of the 3D printed parts [29, 30]. Rao et al. [37] performed a statistical study to identify the influence of layer thickness, infill pattern and extrusion temperature on the tensile strength of a PLA reinforced with short carbon fibers. Kumar et al. [24] performed a statistical study investigating the influence of infill density, printing speed and layer height on a similar composite. The investigation of such influences is relevant to 


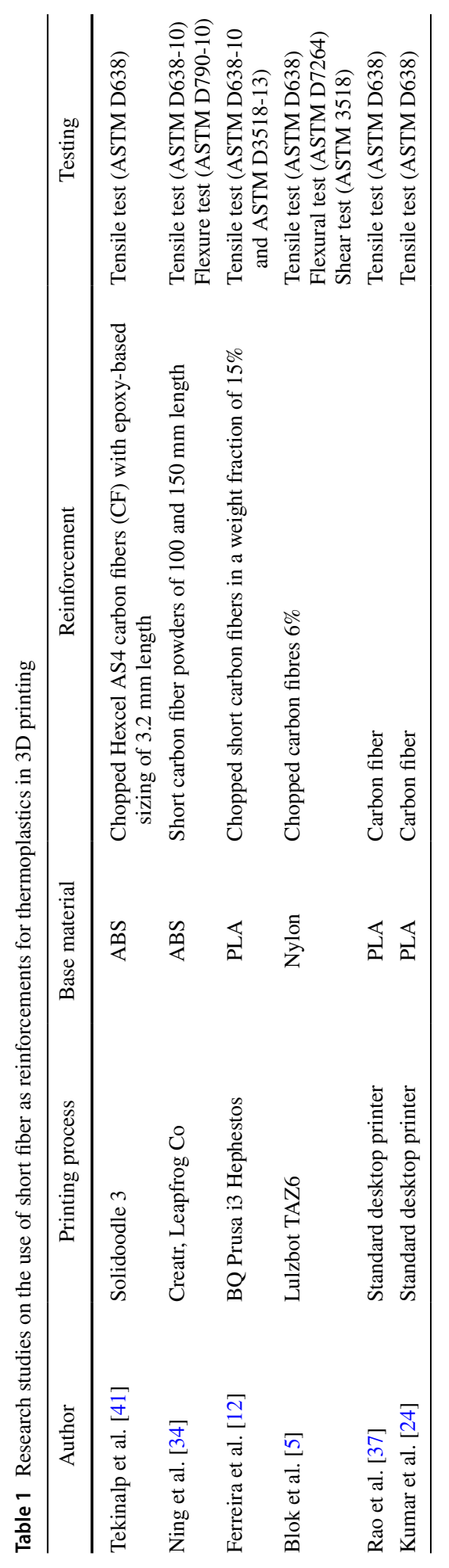


quantify the importance of FFF parameters (as well as their interactions) on properties of 3D printed materials. However, the field still requires new experimental studies to thoroughly evaluate the suitability of these materials, their applications and requirements.

The present study shows an experimental investigation on the mechanical properties of 3D printed specimens, manufactured through FFF technique, using both PLA and reinforced PLA with short carbon fibers. The study aims at analyzing and quantifying the influence of different printing parameters on the tensile strength and studying the fracture behavior. The printing parameters investigated were the number of perimeters (1 and 2), infill density (60, 80 and 100\%), infill pattern (grid, octa and triangular), printing orientation (edgewise, horizontal and vertical) and type of material (PLA and reinforced by short carbon fiber PLA). The study includes the following sections after this introduction. Section 2 presents the materials and methods used to perform the experimental study. Section 3 shows the obtained results that help to calculate the stress-strain diagram for some selected specimens, to carry out a statistical study to evaluate the influence of the printing conditions and to analyze the fracture behavior and fracture strain for some selected specimens based on the porosity. Finally, Sect. 4 identifies the main conclusions of the research work.

\section{Materials and Methods}

The printing materials used in this study were PLA Ivory white, Smartfil (Smart Materials 3D) and reinforced PLA (rPLA), Proto-pasta (Protoplant). The rPLA included 15\% in weight of short carbon fibers. The diameter of both materials was $1.75 \pm 0.03 \mathrm{~mm}$ and their density of 1.24 and $1.3 \mathrm{~g} / \mathrm{cm}^{3}$ for PLA and rPLA, respectively.

The 3D printer used to manufacture the specimens was a 3D BIBO 2 Touch Dual Extruders. The printer was equipped with $0.6 \mathrm{~mm}$ diameter hardened steel nozzles to improve the resistance of the nozzle to the abrasion caused by the reinforcements. Besides, according to Yang et al. [48], the use of large nozzle diameters helps in obtaining higher tensile strength. The maximum nozzle temperature is $270{ }^{\circ} \mathrm{C}$ and the maximum value of material flow is $24 \mathrm{~cm}^{3} / \mathrm{min}$. Finally, the Ultimaker Cura 4.0 software allowed generating the printing code.

The layer-by-layer process may produce unwanted effects such as anisotropy and residual stresses [38, 45]. Because of the anisotropy, the UNE 116,005:2012 standard [42] requires printing the specimens in three different orientations: edgewise, horizontal and vertical. To do that, the standard defines two types of specimens: $1 \mathrm{~A}$ and $1 \mathrm{AV}$, whose length is 150 and $120 \mathrm{~mm}$, respectively. Moreover, the cross-section of the two specimens in the middle section defined by the standard is different, being $4 \times 10 \mathrm{~mm}^{2}$ (1A) and $5 \times 10$ $\mathrm{mm}^{2}(1 \mathrm{AV})$. Figure 1 shows the three orientations to test.

The selection of the printing parameters can notably affect the mechanical properties of the $3 \mathrm{D}$ printed parts $[7,10,21,25,29,33]$. Those related to the layer deposition process (e.g., layer height, infill density, infill pattern, width and number of perimeters, etc.) are of special importance.

The experimental plan includes as factors: number of perimeters (1 and 2), infill density (60, 80 and 100\%) and infill pattern (grid, octa and triangular). Figure 2 shows the three types of infill. Other printing conditions included layer height of $0.2 \mathrm{~mm}$, printing speed of $60 \mathrm{~mm} / \mathrm{s}$, bed temperature of $60^{\circ} \mathrm{C}$ and printing temperature of $210^{\circ} \mathrm{C}$ and $250{ }^{\circ} \mathrm{C}$ for PLA and reinforced PLA, respectively [27]. Moreover, the height of both bottom and top layer 


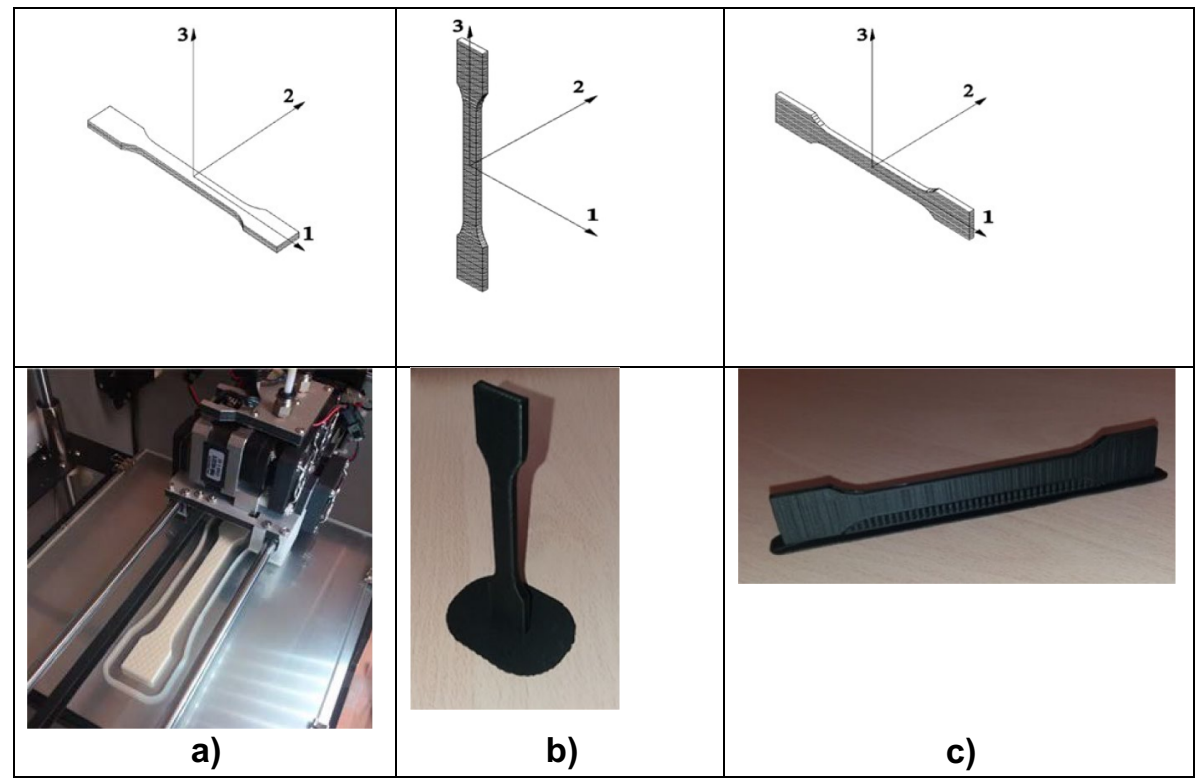

Fig. 1 Specimens according to UNE 116,005: [42] a) Specimen 1A. Horizontal position (PLA), b) Specimen 1AV. Vertical position (reinforced PLA), c) Specimen 1A. Edgewise position (reinforced PLA)

was $0.6 \mathrm{~mm}$. The experiment used a randomized full factorial design of two factors with three levels and one factor with two levels (18 tests per material and orientation). All the tests were performed using the three orientations: edgewise $(\mathrm{E})$, horizontal $(\mathrm{H})$ and vertical (V), but only one specimen was tested for each specific orientation. Based on this, the experimental plan requires printing 108 specimens. Table 2 shows a generic experimental plan to use for each of the orientations and material.

Strength related quantities were chosen as focus of the present assessment, being the tensile strength for the maximum load, which specimens could stand at testing, the main one. Considering the type of specimens here employed and the type of tests performed (tensile), equivalent stiffness (another quantity that can be assessed for a printed material) is mostly influenced by infill density. The larger the infill percentage, the larger the expected final equivalent stiffness. On the other hand, for strength, it is more complicated
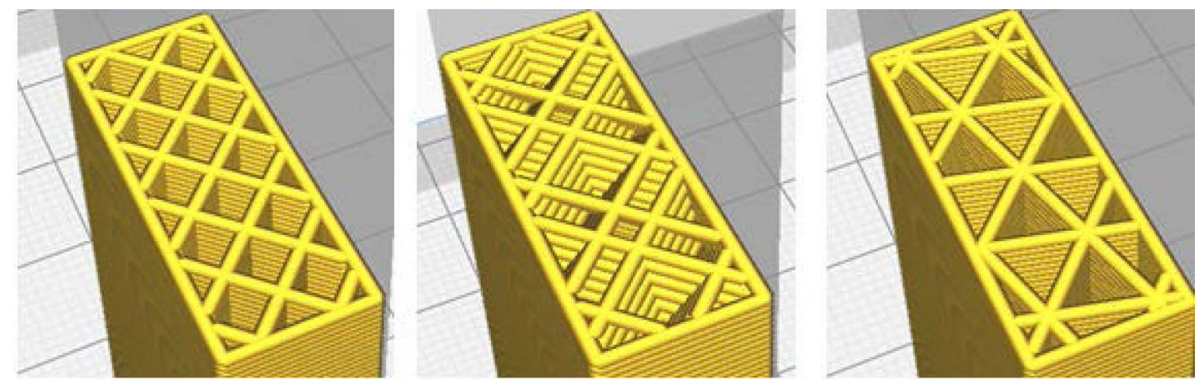

Fig. 2 Infill patterns by Ultimaker Cura 4.0. Left: grid, center: octa, right: triangular 
Table 2 Generic experimental plan

\begin{tabular}{llll}
\hline Test & Infill density $(\%)$ & $\begin{array}{l}\text { Number of } \\
\text { perimeters }\end{array}$ & Infill pattern \\
\hline 1 & 60 & 1 & Grid \\
2 & 80 & 1 & Grid \\
3 & 60 & 1 & Octa \\
4 & 80 & 2 & Octa \\
5 & 100 & 1 & Triangular \\
6 & 80 & 1 & Octa \\
7 & 100 & 1 & Grid \\
8 & 60 & 1 & Triangular \\
9 & 80 & 2 & Grid \\
10 & 100 & 2 & Octa \\
11 & 60 & 2 & Grid \\
12 & 60 & 2 & Triangular \\
13 & 80 & 2 & Triangular \\
14 & 80 & 1 & Triangular \\
15 & 100 & 2 & Triangular \\
16 & 100 & 2 & Grid \\
17 & 100 & 1 & Octa \\
18 & 60 & 2 & Octa \\
\hline
\end{tabular}

to choose a single parameter that mainly influences expected results. Material adhesion during printing, variations in shape of deposited filaments, local imperfections and voids, and any cause that may lead to stress concentrations, are examples of issues that may severely influence strength.

To measure the maximum load during tensile testing, the machine used was an MTS Criterion 43 with an LPS 104 cell and Instron 2716-015 clamping system, using the TW Elite software. The strain rate was $0.5 \mathrm{~mm} / \mathrm{min}$. Tensile testing of the specimens provided the maximum load and the elongation measured due to the crosshead displacement. To calculate the tensile strength, the maximum load was divided by the initial area of the crosssection in the middle part of the specimen. The area of the cross-section was estimated by using the infill density, number and thickness of the perimeters and thickness of the bottom and top layers and it is listed in Table 3 as a percentage related to a full solid area. The

Table 3 Specimens crosssectional area as percentage of full solid area

\begin{tabular}{llcc}
\hline & \multicolumn{2}{c}{ Cross-section/Full solid area (\%) } \\
$\begin{array}{l}\text { Infill density } \\
(\%)\end{array}$ & $\begin{array}{l}\text { Number of } \\
\text { perimeters }\end{array}$ & $\begin{array}{l}\text { Horizontal and } \\
\text { edgewise orientation }\end{array}$ & $\begin{array}{l}\text { Vertical } \\
\text { orientation }\end{array}$ \\
\hline 60 & 1 & 75.4 & 73.2 \\
60 & 2 & 78.7 & 84.2 \\
80 & 1 & 87.7 & 86.6 \\
80 & 2 & 89.4 & 92.1 \\
100 & 1 & 100.0 & 100.0 \\
100 & 2 & 100.0 & 100.0 \\
\hline
\end{tabular}


fracture strain was calculated by means of the relation between the crosshead displacement and the distance between the grips (115 mm for 1A and $85 \mathrm{~mm}$ for $1 \mathrm{AV}$ ) [43].

Image $\mathbf{J}$ software is employed to evaluate the porosity of the fractured section of the specimens. The software allows converting images of the fracture section to 8-bit grayscale images, after removing the background, to measure the area occupied by the pores in percentage. This evaluation was done by measuring the area related to white pixels with RGB value of 255 against the total area of the cross-section, after using the threshold feature.

\section{Results and Discusions}

The experimental plan included the realization of 108 tensile strength tests. Table 4 and Table 5 list the results of the tests in terms of the tensile strength and fracture strain for PLA and rPLA, respectively. The tables show the results classified by means of the orientation used for printing.

The results of tensile strength and fracture strain are close as shown in Tables 4 and 5. In fact, shortly after attaining the maximum load, the specimen suddenly breaks after a short additional elongation, a behavior associated to brittle fracture.

\subsection{Stress-Strain Diagram}

By means of the initial geometry of the specimen and the maximum load and elongation results, it is possible to plot the stress/strain diagram. For clarity, the diagram depicts

Table 4 Results of the PLA tensile tests

\begin{tabular}{|c|c|c|c|c|c|c|}
\hline \multirow[b]{2}{*}{ Test } & \multicolumn{3}{|c|}{ Tensile strength (MPa) } & \multicolumn{3}{|c|}{ Fracture strain $(\mathrm{mm} / \mathrm{mm})$} \\
\hline & Horizontal & Vertical & Edgewise & Horizontal & Vertical & Edgewise \\
\hline 1 & 23.29 & 38.77 & 24.55 & 0.017 & 0.019 & 0.016 \\
\hline 2 & 27.71 & 36.02 & 24.52 & 0.019 & 0.017 & 0.016 \\
\hline 3 & 32.81 & 31.95 & 32.51 & 0.023 & 0.019 & 0.017 \\
\hline 4 & 43.08 & 39.09 & 43.57 & 0.029 & 0.021 & 0.025 \\
\hline 5 & 30.50 & 44.20 & 22.75 & 0.017 & 0.020 & 0.012 \\
\hline 6 & 34.50 & 39.71 & 31.36 & 0.024 & 0.020 & 0.017 \\
\hline 7 & 32.25 & 40.80 & 30.75 & 0.017 & 0.020 & 0.017 \\
\hline 8 & 29.19 & 39.59 & 19.57 & 0.017 & 0.018 & 0.010 \\
\hline 9 & 43.50 & 47.12 & 37.38 & 0.027 & 0.022 & 0.020 \\
\hline 10 & 43.75 & 42.40 & 41.50 & 0.028 & 0.020 & 0.022 \\
\hline 11 & 47.32 & 40.62 & 40.15 & 0.028 & 0.018 & 0.022 \\
\hline 12 & 47.64 & 45.13 & 35.50 & 0.023 & 0.021 & 0.017 \\
\hline 13 & 40.29 & 42.56 & 37.65 & 0.022 & 0.020 & 0.019 \\
\hline 14 & 29.65 & 42.48 & 23.95 & 0.018 & 0.020 & 0.015 \\
\hline 15 & 41.50 & 44.60 & 34.25 & 0.024 & 0.021 & 0.017 \\
\hline 16 & 40.25 & 44.40 & 36.00 & 0.024 & 0.022 & 0.019 \\
\hline 17 & 38.25 & 40.40 & 33.75 & 0.021 & 0.021 & 0.017 \\
\hline 18 & 47.95 & 35.63 & 44.81 & 0.028 & 0.018 & 0.023 \\
\hline
\end{tabular}


Table 5 Results of the rPLA tensile tests

\begin{tabular}{|c|c|c|c|c|c|c|}
\hline \multirow[b]{2}{*}{ Test } & \multicolumn{3}{|c|}{ Tensile strength (MPa) } & \multicolumn{3}{|c|}{ Fracture strain $(\mathrm{mm} / \mathrm{mm})$} \\
\hline & Horizontal & Vertical & Edgewise & Horizontal & Vertical & Edgewise \\
\hline 1 & 23.22 & 23.48 & 19.57 & 0.009 & 0.011 & 0.010 \\
\hline 2 & 23.67 & 22.63 & 21.10 & 0.010 & 0.010 & 0.009 \\
\hline 3 & 28.20 & 16.66 & 27.20 & 0.010 & 0.011 & 0.010 \\
\hline 4 & 41.69 & 22.80 & 43.57 & 0.014 & 0.012 & 0.011 \\
\hline 5 & 26.25 & 25.60 & 17.25 & 0.010 & 0.014 & 0.006 \\
\hline 6 & 31.08 & 22.16 & 28.23 & 0.012 & 0.012 & 0.009 \\
\hline 7 & 27.25 & 24.40 & 29.50 & 0.010 & 0.012 & 0.009 \\
\hline 8 & 21.56 & 21.02 & 16.26 & 0.008 & 0.011 & 0.005 \\
\hline 9 & 40.29 & 25.19 & 30.39 & 0.013 & 0.012 & 0.008 \\
\hline 10 & 40.50 & 20.20 & 43.00 & 0.013 & 0.010 & 0.014 \\
\hline 11 & 42.24 & 19.00 & 37.53 & 0.014 & 0.011 & 0.010 \\
\hline 12 & 42.87 & 20.43 & 31.42 & 0.011 & 0.014 & 0.009 \\
\hline 13 & 38.89 & 24.11 & 37.65 & 0.012 & 0.012 & 0.011 \\
\hline 14 & 19.67 & 25.63 & 22.53 & 0.009 & 0.014 & 0.008 \\
\hline 15 & 38.75 & 24.20 & 34.00 & 0.012 & 0.013 & 0.009 \\
\hline 16 & 35.00 & 23.20 & 32.75 & 0.011 & 0.014 & 0.010 \\
\hline 17 & 32.50 & 21.00 & 26.50 & 0.011 & 0.016 & 0.011 \\
\hline 18 & 39.06 & 12.35 & 43.65 & 0.012 & 0.010 & 0.011 \\
\hline
\end{tabular}

only one test for both materials and for the three orientations. Figure 3 shows the results obtained for test 2 (infill density of $80 \%$ ). In the figure, it is possible to appreciate how the PLA specimens admit higher tensile stress magnitude than that of the reinforced PLA. Particularly, the reinforced PLA shows a more fragile behavior, being the measured strains

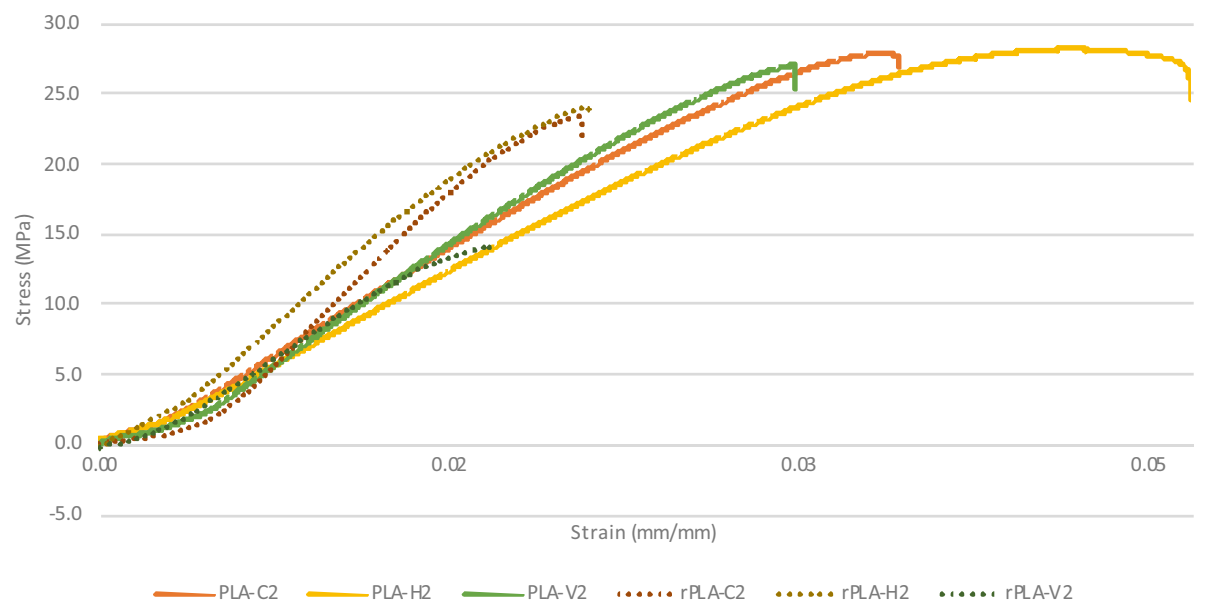

Fig. 3 Stress-strain diagram for test 2 for both PLA and rPLA, $80 \%$ infill density, and for the three studied orientations ( $\mathrm{C}$ - edgewise, $\mathrm{H}$ - horizontal and $\mathrm{V}$ - vertical) 
smaller than those obtained for PLA. The tensile stress that withstands the reinforced material is clearly lower than that of the PLA.

\subsection{Statistical Analysis}

The calculated results for the tensile strength were analyzed by means of the Analysis of Variance (ANOVA) including as factors: orientation, number of perimeters, infill density, infill pattern and material. Table 6 lists all these results. The results were also analyzed by means of the Shapiro-Wilk tests to check the normality of the residuals ( $\mathrm{W}=0.99145$, p-value $=0.7366<\mathrm{W}$ ).

As the significance level for the ANOVA, a p-value of 0.05 is selected [6]. Thus, based on Table 6 , only the type of material, the number of perimeters and the orientation are significant sources of variation of the tensile strength. Alafaghani et al. [1] studied the influence of the infill pattern for infill density of $100 \%$. In their paper, the authors stated that the influence of the infill pattern produced no significant influence on the mechanical properties. Regarding the infill density, Alafaghani et al. [1] and Gunasekaran et al. [15] indicated that the larger the infill density, the larger the tensile strength expected during tensile testing due to an improvement in bonding. However, based on the ANOVA, the variation of tensile strength depending on the infill density is minimal in this experimental study and cannot be considered as a statistically significant source of variation.

The contribution of the significant sources of variation to the total variability is not uniform. In this sense, in Fig. 4, it is possible to appreciate the percent contribution (\%) to the total variability for each of the sources, particularly, the residuals that accounted for $43.5 \%$ of the variability. This may be due to the absence of interactions in the analysis. The other sources of variation explained more than $50 \%$ of the variability. After the residuals, the type of material (24.5\%) and number of perimeters (26.4\%) are the most important sources of variability.

The use of reinforcements produced a reduction of the tensile strength attained by the specimen. Particularly, $24.5 \%$ of the measured variability depended on the type of material. This result agrees well with that presented by Ferreira et al. [12] and Kovan et al. [23]. The type of carbon fiber used as reinforcements (short) can be an adequate explanation for these results. In this case, the polymer matrix mainly supported the load while the reinforcements did not play an important role on that. On the contrary, the reinforcements seem to create a more fragile material. Liu et al. [26] identified that adding short carbon fibers to virgin PLA considerably worsen the mechanical properties. It should be noted that it is still

Table 6 Results of ANOVA for the tensile strength

\begin{tabular}{llcccr}
\hline Factor & $\begin{array}{l}\text { Degrees of } \\
\text { freedom }\end{array}$ & Sum of squares & Mean squares & F-Value & $\operatorname{Pr}(>\mathrm{F})$ \\
\hline Infill density & 2 & 55.1 & 27.56 & 0.7375 & $4.809 \mathrm{E}-01$ \\
Infill pattern & 2 & 153.6 & 76.81 & 2.0556 & $1.334 \mathrm{E}-01$ \\
Orientation & 2 & 328.5 & 164.25 & 4.3958 & $1.482 \mathrm{E}-02$ \\
Material & 1 & 2085.34 & 2085.34 & 55.8107 & $3.207 \mathrm{E}-11$ \\
Perimeters & 1 & 2245.6 & 2245.6 & 60.1003 & $8.107 \mathrm{E}-12$ \\
Residuals & 99 & 3699.1 & 37.36 & - & \\
Total & 107 & 8512.14 & & & \\
\hline
\end{tabular}




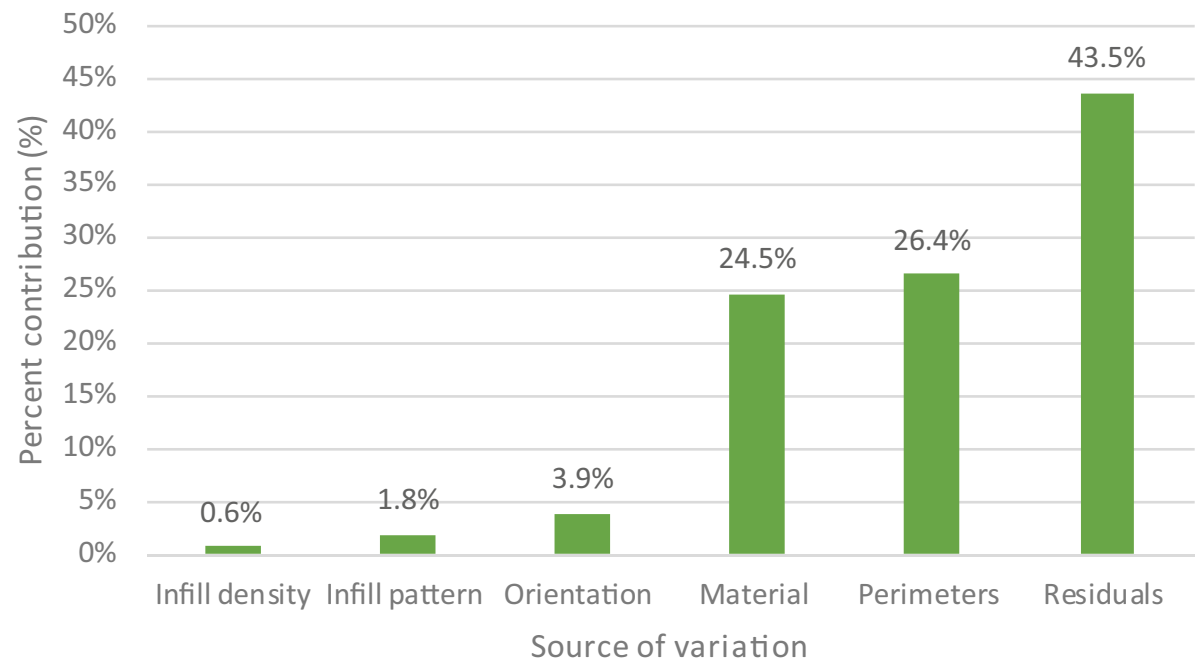

Fig. 4 Percent contribution (\%) for all the sources of variation studied

possible to improve the results of rPLA by optimizing the printing configuration based on the selected parameters, and by performing additional research in other factors such as the bed and printing temperature or nozzle size.

Among the significant sources of variation, the factor with one of the highest influence on the tensile strength was the number of perimeters (Fig. 4). Particularly, the resistance was increased when two perimeters were used for both PLA and rPLA materials as shown in Fig. 5. The number of perimeters influences the amount of material in a particular crosssection. This result agrees well with the findings presented by Lanzotti et al. [25]. Similarly, Fountas et al. [13] showed also how tensile strength increases when the shell thickness (i.e., related to the number of perimeters) increases. When evaluating the influence of the material, the reinforced PLA showed lower values for the tensile strength at both one and two perimeters.

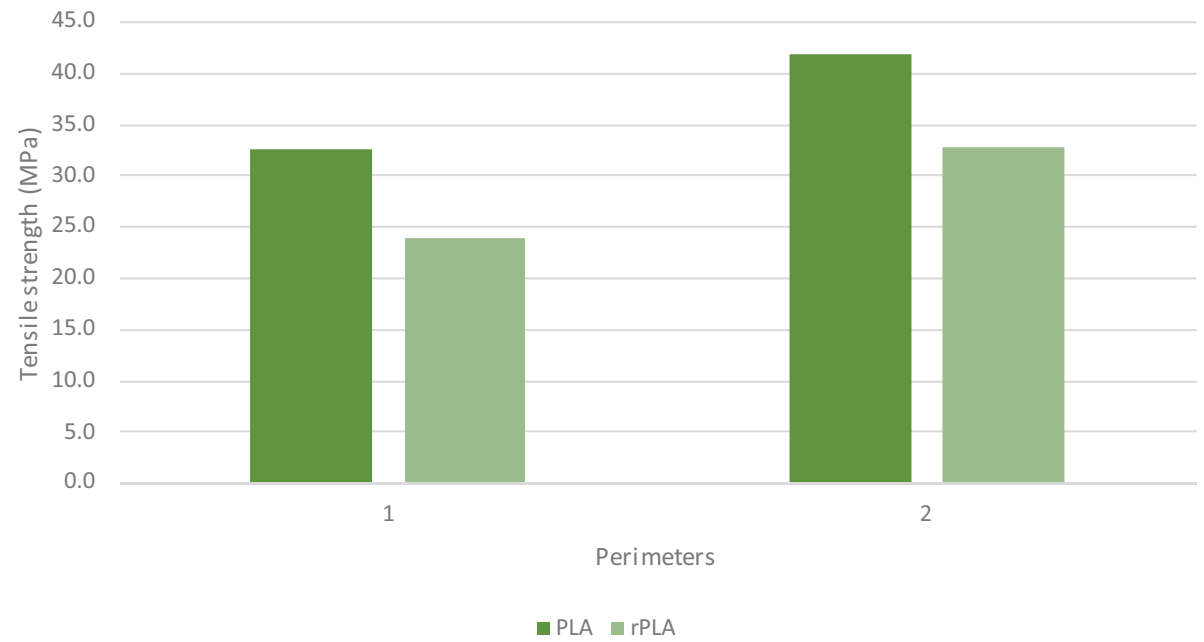

Fig. 5 Tensile strength versus the number of perimeters for both PLA and rPLA 
The orientation used in printing is expected to condition the tensile strength. Particularly, the maximum strength should be obtained when the printing orientation is the same as the direction used in the tensile testing [45]. Kamaal et al. [20] showed results in which the tensile strength of carbon fiber reinforced PLA is slightly lower when printing in vertical orientation than when using the other two orientations. Although, the ANOVA highlighted this factor as statistically significant, the contribution to the variability was minimal. By way of caution, it should be considered that some previously published studies related to the orientation are based on one single specimen, while, in the present study, two different specimens (i.e., 1A and $1 \mathrm{AV}$ ) were used. Moreover, it should be noted the effect of the influence of the bottom and top layers of $0.6 \mathrm{~mm}$ thickness in the edgewise and horizontal orientations, when using two perimeters. This creates a slightly weaker contour and, thus, a weaker cross-section than that of the vertical orientation (see Table 3).

\subsubsection{Fracture Surfaces of Selected Specimens}

In Fig. 6, it is possible to observe the fracture surface of the specimen for tests 4,9 and 13 that correspond to octa, grid and triangular infill patterns, respectively. The parameters used to perform these tests were layer height of $0.2 \mathrm{~mm}$, infill density of $80 \%$, two

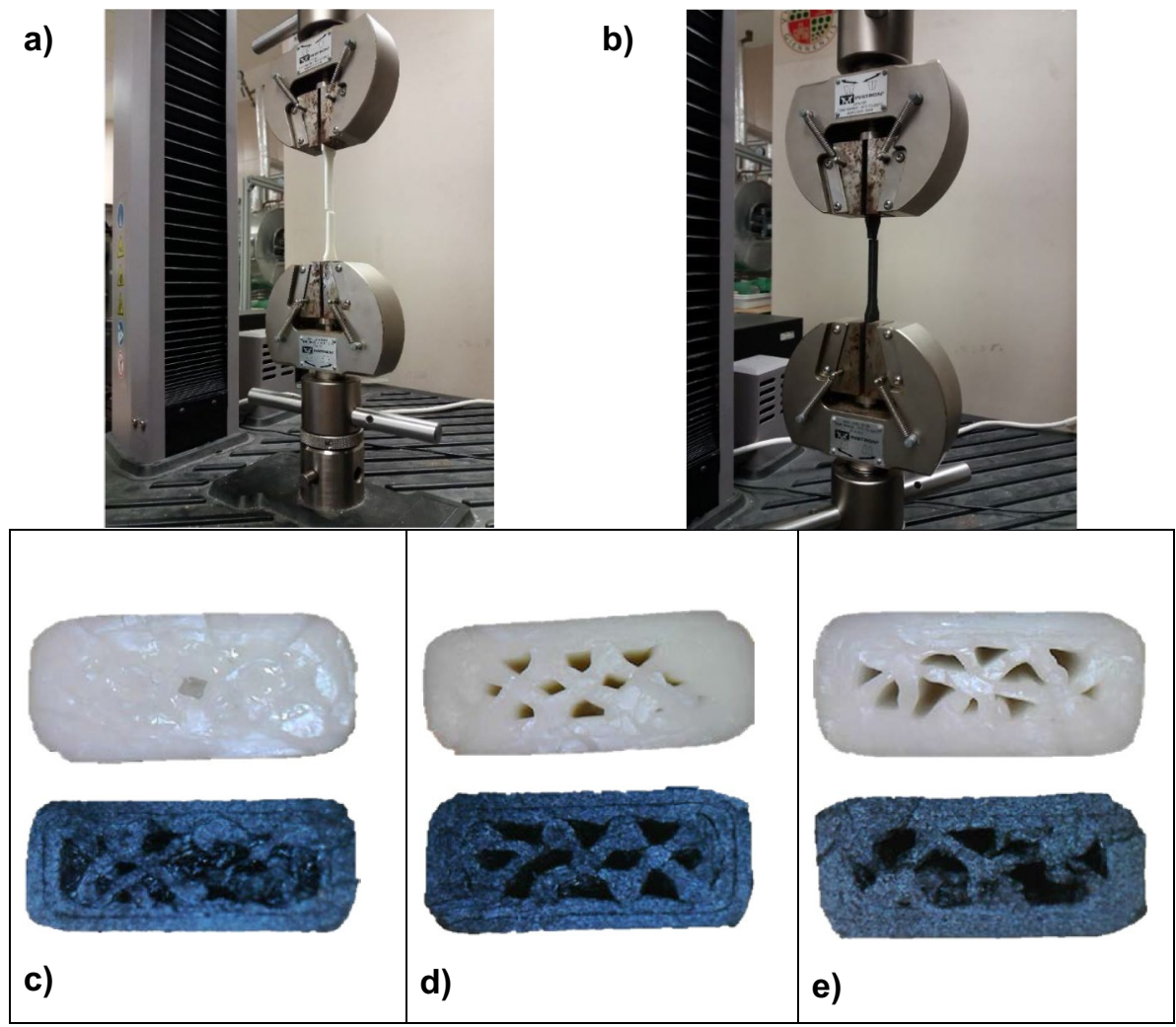

Fig. 6 Tensile test and fractured specimens: a) PLA testing, b) Reinforced rPLA testing, c) Test 4: PLA (up) and rPLA (down), d) Test 9: PLA (up) and rPLA (down), e) Test 13: PLA (up) and rPLA (down) 
Table 7 Porosity (\%) in the fractured section of the selected specimens

$$
\text { Porosity (\%) }
$$

\begin{tabular}{lll} 
& PLA & rPLA \\
\hline Test 4 & 1 & 20 \\
Test 9 & 6 & 15 \\
Test 13 & 8 & 15 \\
\hline
\end{tabular}

perimeters and vertical orientation. The true cross-section of the fracture zone is higher for the PLA specimens. This is due the occurrence of undesired porosity. Tekinalp et al. [41], when using carbon fiber reinforcements, also identified the occurrence of porosity in their experimental study. As Özen et al. [35] stated, the bonding is not perfect, so partially bonded filaments and voids compose these 3D printed composite specimens. Particularly, as shown in Table 7, the porosity related to the fractured section, calculated by means of the Image $\mathbf{J}$ software, notably increases when using reinforcements, and changes from $1-8 \%$ to $15-20 \%$. Besides, from Fig. 6, it is possible to notice how the bonding between the two perimeters is even stronger when using PLA (because some grooves that mark the limits between perimeters are visible in rPLA specimens and are not for PLA).

The presence of porosity is especially important when studying the fracture during testing. In this sense, Fig. 7 shows the fracture strain calculated by means of the crosshead displacement against the distance between the grips. In the figure, it is possible to appreciate how the strain for PLA is larger than that of rPLA. Thus, the reinforcement clearly provides brittleness to the specimens. It is also highlighted the possible influence of the used nozzle. The diameter of the nozzle might not have had a suitable size to let the short carbon fibers align with the material flow. It is also highlighted the possible influence of the carbon fiber percentage in the results. Ning et al. [34] showed how when increasing the carbon fiber percentage using ABS matrix from 5 to $10 \%$, the tensile strength diminished. In the present study, the percentage of carbon fiber was even higher, $15 \%$ in weight. Moreover, the PLA itself has a mechanical behavior closer to brittle in comparison to ABS.

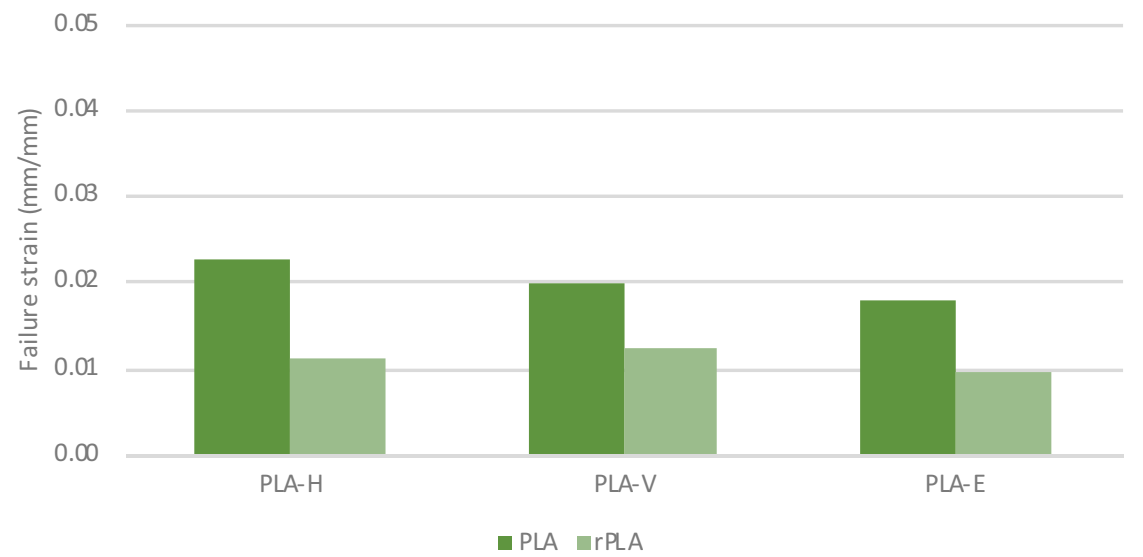

Fig. 7 Failure strain for the different studied orientations 
Furthermore, by observing the results in this subsection, it is possible to hypothesize that the perimeters had a higher influence on specimens' strengths because they seem to be areas of deposited material with improved adhesion, in comparison to infill patterns. Perimeters are of simpler and more straightforward deposition in comparison to infills, which could assure more consistent material flow and areas of improved adhesion. Moreover, in the present case, two perimeters fill a considerably bigger portion of the specimen cross section with a region of good adhesion, in comparison to the one perimeter case.

\section{Conclusions}

In recent years, 3D printing is increasing its applications in a wide range of industrial sectors. New materials are being developed and tested for 3D printing purposes, for instance reinforced polymers. The present study shows an experimental investigation of the mechanical resistance of 3D printed parts manufactured of PLA and short carbon fiber reinforced PLA. The main conclusions of the study are as follows:

- The stress-strain diagram of a selected group of specimens showed how the virgin material outperformed the reinforced one in terms of attained tensile stress and strain.

- The full factorial experiment carried out to evaluate the influence of the orientation, infill density, infill pattern, number of perimeters and type of material on the tensile strength identified as statistically significant factors both the type of material and number of perimeters.

- The effect of the number of perimeters was to increase the tensile strength as their values were increased. Both tested materials followed this trend.

- Regarding the type of material, the use of short carbon fiber reinforcements in the PLA did not produce improvements in the mechanical strength of tested specimens, as expected from previous literature results. This behavior might have been favored due to a higher level of porosity of the here studied samples cross-section.

Funding Open Access funding provided thanks to the CRUE-CSIC agreement with Springer Nature.

Data Availability Authors can confirm that all relevant data are included in the article and/or its supplementary information files. Source data for Fig. 3 are available upon reasonable request to the authors.

Open Access This article is licensed under a Creative Commons Attribution 4.0 International License, which permits use, sharing, adaptation, distribution and reproduction in any medium or format, as long as you give appropriate credit to the original author(s) and the source, provide a link to the Creative Commons licence, and indicate if changes were made. The images or other third party material in this article are included in the article's Creative Commons licence, unless indicated otherwise in a credit line to the material. If material is not included in the article's Creative Commons licence and your intended use is not permitted by statutory regulation or exceeds the permitted use, you will need to obtain permission directly from the copyright holder. To view a copy of this licence, visit http://creativecommons.org/licenses/by/4.0/. 


\section{References}

1. Alafaghani, A., Qattawi, A., Alrawi, B., Guzman, A.: Experimental Optimization of Fused Deposition Modelling Processing Parameters: A Design-for-Manufacturing Approach. Procedia Manufact. 10, 791-803 (2017)

2. Altıparmak, S.C., Yardley, V.A., Shi, Z., Lin, J.: Challenges in additive manufacturing of high-strength aluminium alloys and current developments in hybrid additive manufacturing. Internatl. J. Lightweight Mater. Manufact. 4(2), 246-261 (2021)

3. Antony, S., Cherouat, A., Montay, G.: Fabrication and Characterization of Hemp Fibre Based 3D Printed Honeycomb Sandwich Structure by FDM Process. Appl. Compos. Mater. 27, 935-953 (2020)

4. Bhushan, B., Caspers, M.: An overview of additive manufacturing (3D printing) for microfabrication. Microsyst. Technol. 23, 1117-1124 (2017)

5. Blok, L.G., Longana, M.L., Yu, H., Woods, B.K.S.: An investigation into 3D printing of fibre reinforced thermoplastic composites. Addit. Manuf. 22, 176-186 (2018)

6. Carou, D., Rubio, E.M., Agustina, B., Marín, M.M.: Experimental study for the effective and sustainable repair and maintenance of bars made of Ti-6Al-4V alloy. Application to the aeronautic industry. J. Clean. Prod. 164, 465-475 (2017)

7. Chacon, J.M., Caminero, M.A., Garcia-Plaza, E., Nunez, P.J.: Additive manufacturing of PLA structures using fused deposition modeling: Effect of process parameters on mechanical properties and their optimal selection. Mater. Des. 124, 143-157 (2017)

8. Chawla, K.: Composite Materials: Science and Engineering. Springer Science+Business Media New York. Chapter 1: Introduction. (2012)

9. Di Falco, S.: Optimization of process parameters for Directed Energy Deposition of IN718 nickelbased superalloy. Master of Science Thesis. Politecnico di Torino. (2019)

10. Durao, L. F., Barkoczy, R., Zancull, E., Ho, L., Bonnard, R.: Optimizing additive manufacturing parameters for the fused deposition modeling technology using a design of experiments. Progress in Additive Manufacturing. Ed. Springer. (2019)

11. Dutra, T.A., Ferreira, R.T.L., Resende, H.B., Guimarães, A.: Mechanical characterization and asymptotic homogenization of 3D-printed continuous carbon fiber-reinforced thermoplastic. J. Braz. Soc. Mech. Sci. Eng. 41, 133 (2019)

12. Ferreira, R.T.L., Amatte, I.C., Dutra, T.A., Burger, D.: Experimental characterization and micrography of 3D printed PLA and PLA reinforced with short carbon fibers. Compos. B Eng. 124, 88-100 (2017)

13. Fountas, N.A., Kostazos, P., P., Pavlidis, H., Antoniou, V., Manolakos, D.E., Vaxevanidis, N.M.: Experimental investigation and statistical modelling for assessing the tensile properties of FDM fabricated parts. Procedia Structural Integrity 26, 139-146 (2020)

14. Gonzalez-Henriquez, C., Sarabia-Vallejos, M.A., Rodriguez-Hernandez, J.: Polymers for additive manufacturing and 4D-printing: materials, methodologies, and biomedical applications. Prog. Polym. Sci. 94, 57-116 (2019)

15. Gunasekaran, K.N., Aravinth, V., Kumaran, C.B.M., Madhankumar, K., Kumar, S.P.: Investigation of mechanical properties of PLA printed materials under varying infill density. Materials Today: Proceedings 45(2), 1849-1856 (2021)

16. Guo, N., Leu, M.: Additive manufacturing: technology, applications and research needs. Front. Mech. Eng. 8(3), 215-243 (2013)

17. Heidari-Rarani, M., Rafiee-Afarani, M., Zahedi, A.M.: Mechanical characterization of FDM 3D printing of continuous carbon fiber reinforced PLA composites. Compo. Part B: Eng. 175:107147 (2019)

18. Horvath, J.: A Brief History of 3D Printing. Mastering 3D Printing, 3-10. Ed. Springer. (2014)

19. Jakus, A.: Chapter 1: An Introduction to 3D Printing-Past, Present, and Future Promise. 3D Printing in Orthopaedic Surgery, 1-15. (2019)

20. Kamaal, M., Anas, M., Rastogi, H., Bhardwaj, N., Rahaman, A.: Effect of FDM process parameters on mechanical properties of 3D-printed carbon fibre-PLA composite. Prog. Add. Manufact. 6, 63-69 (2021)

21. Kiendl, J, Gao, C.: Controlling toughness and strength of FDM 3D-printed PLA components through the raster layup. Compos. Part B: Eng. 180(1):107562 (2020)

22. Kikuchi, B.C., Bussamra, F.L.S., Donadon, M.V., Ferreira, R.T.L., Sales, R.C.M.: Moisture effect on the mechanical properties of additively manufactured continuous carbon fiber-reinforced nylon-based thermoplastic. Polym. Compos. 41(12), 5227-5245 (2020)

23. Kovan, V., Tezel, T., Camurlu, H., Topal, E.: Effect of printing parameters on mechanical properties of 3D printed pla/carbon fiber composites. Engineering Faculty - Akdeniz University, Turkey, Department of Mechanical Engineering (2018) 
24. Kumar, M.A., Khan, M.S., Mishra, S.B.: Effect of fused deposition machine parameters on tensile strength of printed carbon fiber reinforced PLA thermoplastics. Materials Today: Proceedings 27(2), 1505-1510 (2020)

25. Lanzotti, A., Grasso, M., Staiano, G., Martorelli, M.: The impact of process parameters on mechanical properties of parts fabricated in PLA with an open-source 3-D printer. Rapid Prototyp. J. 21, 604-617 (2015)

26. Liu, Z., Lei, Q., Xing, S.: Mechanical characteristics of wood, ceramic, metal and carbon fiber-based PLA composites fabricated by FDM. J. Market. Res. 8(5), 3741-3751 (2019)

27. Maqsood, N., Rimašauskas, M.: Characterization of carbon fiber reinforced PLA composites manufactured by fused deposition modeling. Compos. Part C: Open Access 4:100112 (2021)

28. Mehrpouya, M., Dehghanghadikolaei, A., Fotovvati, B., Vosooghnia, A., Emamian, S.S., Gisario, A.: The Potential of Additive Manufacturing in the Smart Factory Industrial 4.0: A Review. Appl. Sci. 9, 3865 (2019)

29. de Macedo, R.Q., Ferreira, R.T.L., Jayachandran, K.P.: Determination of mechanical properties of FFF 3D printed material by assessing void volume fraction, cooling rate and residual thermal stresses. Rapid Prototyp. J. 25(10), 1661-1683 (2019)

30. de Macedo, R.Q., Ferreira, R.T.L., Gleadall, A.; Ashcroft, I.: VOLCO-X: Numerical simulation of material distribution and voids in extrusion additive manufacturing. Add. Manufact. 40, 101900 (2021)

31. Ming, Y., Zhang, S., Han, W., Wang, B., Duan, Y., Xiao, H.: Investigation on process parameters of 3D printed continuous carbonfiber-reinforced thermosetting epoxy composites. Add. Manufact. 33: $101184(2020)$

32. Murr, L., Johnson, W.: 3D metal droplet printing development and advanced materials additive manufacturing. J. Market. Res. 6(1), 77-89 (2017)

33. Naranjo-Lozada, J., Ahuett-Garza, H., Orta-Castanon, P., Verbeeten, W., Saiz-Gonzalez, D.: Tensile properties and failure behavior of chopped and continuous carbon fiber composites produced by additive manufacturing. Addit. Manuf. 26, 227-241 (2019)

34. Ning, F., Cong, W., Qiu, J., Wei, J., Wang, S.: Additive manufacturing of carbon fiber reinforced thermoplastic composites using fused deposition modeling. Compos. B 80, 369-378 (2015)

35. Özen, A., Abali, B.E., Völlmecke, C., Gerstel, J., Auhl, D.: Exploring the Role of Manufacturing Parameters on Microstructure and Mechanical Properties in Fused Deposition Modeling (FDM) Using PETG. Appl. Compos. Mater. (2021)

36. Peng, T., Kellens, K., Tang, R., Chen, C., Chen, G.: Sustainability of additive manufacturing: An overview on its energy demand and environmental impact. Addit. Manuf. 21, 694-704 (2018)

37. Rao, V.D.P., Rajiv, P., Geethika, V.N.: Effect of fused deposition modelling (FDM) process parameters on tensile strength of carbon fibre PLA. Materials Today: Proceedings 18(6), 2012-2018 (2019)

38. Rodríguez-Panes, A., Claver, J., Camacho, A.M.: The influence of manufacturing parameters on the mechanical behaviour of PLA and ABS pieces manufactured by FDM: A comparative analysis. Materials 11, 1333 (2018)

39. Schmid, M.: Laser Sintering with Plastics. Laser Sintering with Plastics, 1-13 (2018)

40. Staab, G.: Introduction to composite materials. Laminar Composites (Second Edition), 1-16 (2015)

41. Tekinalp, H.L., Kun, V., Velez-Garcia, G.M., Duty, C.E., Love, L.J., Naskar, A.K., Blue, C.A., Ozcan, S.: Highly oriented carbon fiber-polymer composites via additive manufacturing. Compos. Sci. Technol. 105, 144-150 (2014)

42. UNE 116005.: Fabricación por adición de capas en materiales plásticos. Fabricación aditiva. Preparación de probetas. (2012)

43. UNE 527:1.: Plásticos. Determinación de las propiedades en tracción. Parte 1: Principios generales. (2012)

44. Wang, X., Jiang, M., Zhou, Z., Gou, J., Hui, D.: 3D printing of polymer matrix composites: A review and prospective. Compos. B Eng. 110, 442-458 (2017)

45. Wang, S., Ma, Y., Deng, Z., Zhang, S., Cai, J.: Effects of fused deposition modeling process parameters on tensile, dynamic mechanical properties of 3D printed polylactic acid materials. Polym. Test. 86: 106483 (2020)

46. Wendel, B., Rietzel, D., Kuhnlein, F., Feulner, R., Hulder, G., Schmachtenberg, E.: Additive Processing of Polymers. Macromole. J. Mater. Eng. 293, 799-809 (2008)

47. Werken, N. van de., Tekinalp, H., Khanbolouki, P., Ozcan, S., Williams, A., Tehrani, M.: Additively manufactured carbon fiber-reinforced composites: State of the art and perspective. Add. Manufact. 31:100962 (2020)

48. Yang, L., Li, S., Li, Y., Yang, M., Yuan, Q.: Experimental Investigations for Optimizing the Extrusion Parameters on FDM PLA Printed Parts. JMEPEG 28, 169-182 (2019) 
49. Yao, T., Ye, J., Deng, Z., Zhang, K., Ma, Y., Ouyang, H.: Tensile failure strength and separation angle of FDM 3D printing PLA material: Experimental and theoretical analyses. Compos. Part B 188:107894 (2020)

50. Zhuo, P., Li, S., Ashcroft, I.A., Jones, A.I.: Material extrusion additive manufacturing of continuous fibre reinforced polymer matrix composites: A review and outlook. Compos. Part B: Eng. 224, 109143 (2021)

Publisher's Note Springer Nature remains neutral with regard to jurisdictional claims in published maps and institutional affiliations. 